\title{
Age-Related Differences in Vasoconstrictor Responses to Isoprostanes in Piglet Pulmonary and Mesenteric Vascular Smooth Muscle
}

\author{
GEMA GONZÁLEZ-LUIS, FRANCISCO PÉREZ-VIZCAÍNO, FERMÍN GARCÍA-MUÑOZ, \\ JO G.R. DE MEY, CARLOS E. BLANCO, AND EDUARDO VILLAMOR
}

\begin{abstract}
Department of Pediatrics, University Hospital Maastricht, Research Institute Growth and Development (GROW) [G.G.-L., C.E.B., E.V.], Department of Pharmacology and Toxicology, Cardiovascular Research Institute Maastricht (CARIM) [J.G.R.D.M.], University of Maastricht, 6202 AZ Maastricht, The Netherlands, Division of Neonatology, Department of Pediatrics [G.G.-.L., F.G.-.M.], Hospital Universitario Materno-Infantil de Canarias, 35015 Las Palmas de Gran Canaria, Spain, Department of Pharmacology [F.P.-.V.], School of Medicine, Universidad Complutense, 28040 Madrid, Spain
\end{abstract}

\begin{abstract}
Isoprostanes are prostaglandin (PG)-like compounds produced nonenzymatically by free radical-catalyzed peroxidation of arachidonic acid. Isoprostanes evoke potent vascular effects but their actions in the neonatal vasculature are poorly known. We aimed to study the effects of 8-iso-PGE 1,8 -iso- $\mathrm{PGE}_{2}, 8$-iso- $\mathrm{PGF}_{1 \alpha}$, 8-iso$\mathrm{PGF}_{1 \beta}, 8$-iso-PGF ${ }_{2 \alpha}$, and 8-iso- $\mathrm{PGF}_{2 \beta}$ in pulmonary arteries (PA), pulmonary veins $(\mathrm{PV})$, and mesenteric arteries (MA) from newborn and 2-wk-old piglets. Isoprostanes produced concentrationdependent contractions of PA, PV, and MA (magnitudes up to 1.5to 2-fold greater than the responses to $62.5 \mathrm{mM} \mathrm{KCl}$ ) but they were markedly less potent vasoconstrictors than the thromboxane $\mathrm{A}_{2}$ $\left(\mathrm{TXA}_{2}\right)$ mimetic U46619. Neonatal PA were more sensitive to 8-iso-PGF ${ }_{1 \alpha}, 8$-iso-PGF ${ }_{1 \beta}$, and 8-iso-PGF $2 \beta$ than 2-wk-old PA. Neonatal PV were more sensitive to 8-iso- $\mathrm{PGE}_{2}$ and 8-iso-PGF ${ }_{1 \alpha}$ and neonatal MA were more sensitive to 8-iso- $\mathrm{PGE}_{2}, 8$-iso- $\mathrm{PGF}_{1 \alpha}$, 8 -iso-PGF ${ }_{1 \beta}, 8$-iso- $\mathrm{PGF}_{2 \alpha}$, and 8-iso- $\mathrm{PGF}_{2 \beta}$ than the corresponding 2-wk-old vessels. The sensitivity to U46619 decreased with postnatal age in MA but did not change in PA and PV. The contractile responses to all the isoprostanes and to $\mathrm{U} 46619$ were reverted by the $\mathrm{TXA}_{2}$ receptor (TP) antagonist SQ 29,548. Moreover, isoprostane-
\end{abstract}

\section{ABSTRACT}

evoked contractions in 2-wk-old PA were reduced by inhibitors of tyrosine kinase (genistein) and Rho kinase (Y 27632 and hydroxyfasudil) but not by inhibitors of protein kinase C (chelerythrine), mitogen-activated protein kinase kinase (PD 98059) or p38-kinase (SB 203580). In conclusion, isoprostanes produced compound-, tissue-, and age-dependent constriction of neonatal porcine pulmonary and mesenteric vascular smooth muscle. Isoprostane-evoked PA vasoconstriction involved TP receptors and activation of tyrosine kinases and Rho kinases. (Pediatr Res 57: 845-852, 2005)

\section{Abbreviations}

COX, cyclooxygenase

EC50, half-maximum effective concentration

MA, mesenteric artery

PA, pulmonary artery

PG, prostaglandin

PKC, protein kinase $\mathrm{C}$

PV, pulmonary vein

TP, thromboxane $\mathrm{A}_{2}$ receptor

TXA $_{2}$, thromboxane $\mathrm{A}_{2}$
Isoprostanes are PG-like compounds formed in vivo by the free radical-catalyzed peroxidation of arachidonic acid, a reaction independent of the COX enzyme (1-3). They are generated initially at the site of a free radical attack of esterified arachidonate in cell membranes from which they are cleaved, presumably by

Received August 2, 2004; accepted November 2, 2004.

Correspondence: E. Villamor, M.D., Ph.D., Department of Pediatrics, University Hospital Maastricht. P. Debyelaan 25, PO Box 5800, 6202 AZ Maastricht, The Netherlands; e-mail: eiv@paed.azm.nl

G.G.-L. was supported by a grant of Fundación Canaria de Investigación y Salud (FUNCIS-2/2002). F.P.-V. was supported by Comunidad Autónoma de Madrid (CAM) (08.4/0036.2001) and Comisión Interministerial de Ciencia y Technologia (CICYT) (SAF 2002/02304) grants.

DOI: 10.1203/01.PDR.0000161411.01208.83 phospholipases (2,3). Isoprostanes are used clinically and experimentally as markers for many disease states in which oxidative stress is a prominent feature, including asthma, myocardial and renal ischemia-reperfusion injury, atherosclerosis, pulmonary hypertension, and hypercholesterolemia (4-6). However, isoprostanes are much more than inert markers and have been shown to possess biologic activity in whole-animal, isolated tissue, and cell-based systems $(6,7)$. In the vascular system, isoprostanes exert important effects that range from powerful vasoconstriction to complete vasodilatation, depending on the particular isoprostane, tissue, and species studied (7).

The neonatal period appears to be particularly interesting for the study of the biologic effects of isoprostanes because the 
3 -fold increase in the arterial oxygen tension after birth renders a higher susceptibility to oxidant-mediated lipid peroxidation $(8,9)$. Moreover, isoprostanes have been proposed as markers to quantify oxidative stress in perinatal asphyxia (10), prematurity (11), periventricular leukomalacia (12), bronchopulmonary dysplasia (12), and neonatal pulmonary disease (13).

At birth, the placenta is replaced in its respiratory function by the lungs and in its nutritional function by the gastrointestinal tract. The unique hemodynamic changes that this process of transition implies for the pulmonary and mesenteric circulations have been extensively studied but remain incompletely understood. Numerous studies demonstrated ontogenic differences in contractile and relaxing responses of pulmonary and mesenteric vessels (14-19). However, despite the fast-growing body of literature addressing isoprostanes and their effects on diverse vascular smooth muscles, data regarding the development of isoprostane effects in newborn vasculature are scarce. Truog et al. (20), observed that 8-iso-PGF2 $\alpha$ induced marked pulmonary vasoconstriction in 2-wk-old piglets. In addition, Belik et al. (9) have shown that the 1-wk-old rat pulmonary vascular response to 8 -iso-PGF $2 \alpha$ is clearly distinct from the adult. This age-dependent difference in force development was similar to the pattern previously described during stimulation of rat pulmonary artery with other agonists, including the $\mathrm{TxA}_{2}$ analog $\mathrm{U} 46619$, which appears to act via the same receptor as 8 -iso-PGF $2 \alpha(9,21)$. No study has characterized the response to isoprostanes in neonatal systemic vessels.

In the present study, we hypothesized that the vascular response to isoprostanes in early postnatal life is developmentally regulated in porcine pulmonary and mesenteric vessels. Therefore, we aimed to study the effects of several E-ring (8-iso-PGE ${ }_{1}$ and 8-iso- $\mathrm{PGE}_{2}$ ) and F-ring (8-iso-PGF ${ }_{1 \alpha}, 8$-iso$\mathrm{PGF}_{1 \beta}, 8$-iso- $\mathrm{PGF}_{2 \alpha}, 8$-iso- $\mathrm{PGF}_{2 \beta}$ ) isoprostanes on contractile activity in isolated pulmonary arteries (PA), pulmonary veins $(\mathrm{PV})$, and mesenteric arteries (MA) from newborn and 2-wkold piglets.

\section{METHODS}

Tissue preparation. All experiments were carried out in accordance with the European Animals Act 1986 (Scientific Procedures) and approved by the institutional review board. Neonatal piglets aged $12-24 \mathrm{~h}(n=24)$ and $2 \mathrm{wk}$ $(n=25)$, obtained from a local farm, were killed by exsanguination after being anesthetized with sodium pentobarbitone $\left(100 \mathrm{mg} \cdot \mathrm{kg}^{-1}\right)$. The stomachs of all subjects were distended with milk curd at the time of sacrifice and their small intestine was filled with chyme, confirming that they had been fed. This observation is important, because it has been reported that the initial feedings after birth, specifically in the first $18 \mathrm{~h}$ of postnatal life, produce significant changes on vasoactive mediators within the piglet mesenteric vasculature (19). The lungs and intestines were rapidly immersed in cold $\left(4^{\circ} \mathrm{C}\right) \mathrm{Krebs}$-Ringer bicarbonate buffer (composition in $\mathrm{mmol} \mathrm{L}^{-1}: \mathrm{NaCl}, 118.5 ; \mathrm{KCl}, 4.75 ; \mathrm{MgSO}_{4}$ . $7 \mathrm{H}_{2} \mathrm{O}, 1.2 ; \mathrm{KH}_{2} \mathrm{PO}_{4}, 1.2 ; \mathrm{NaHCO}_{3}, 25.0 ; \mathrm{CaCl}_{2}, 2.5$; glucose, 5.5). PA, PV (third-fourth branch, in situ external diameter 1-2 mm), and MA with a similar in situ external diameter (distal half of the MA trunk) were carefully dissected free of surrounding tissue and cut into rings of $2-3 \mathrm{~mm}$ of length under a dissection microscope.

Isometric force measurement. After dissection, two L-shaped stainlesssteel wires were inserted into the arterial lumen and the rings were introduced in Allhin organ chambers filled with Krebs solution at $37^{\circ} \mathrm{C}$, gassed with $95 \%$ $\mathrm{O}_{2} / 5 \% \mathrm{CO}_{2}$. One wire was attached to the chamber and the other to an isometric force-displacement transducer (model PRE 206-4, Cibertec, Madrid, Spain). The isometric force signal was amplified, A/D converted (PowerLab, ADInstruments Pty., Castle Hill, Australia), and recorded (Chart v3.4, ADInstruments Pty.). An optimal resting tension of $0.3 \mathrm{~g}$ (PA of 12- to $24 \mathrm{~h}$-old animals), $0.5 \mathrm{~g}$ (PA of 2-wk-old animals and PV of both groups), $1 \mathrm{~g}$ (MA of 12- to 24 h-old animals), or $2 \mathrm{~g}$ (MA of 2-wk-old animals) was applied to the vascular segments, as determined from previous experiments $(14,15)$. Tissues were allowed to equilibrate for $60-90 \mathrm{~min}$. During this period, they were restretched and washed every $30 \mathrm{~min}$ with warm Krebs solution. Before commencing the experiments, the tissues were transiently challenged with 62.5 $\mathrm{mM} \mathrm{KCl}$ to assess the functional state of each vessel and to establish a reference nonreceptor-mediated contraction for standardization of contractile responses to the isoprostanes. This method of standardization was chosen because it takes into account not only the vascular smooth muscle mass but also the functional capacity of the vascular rings to develop contraction. The contractile response to $\mathrm{KCl}$ of piglet pulmonary and mesenteric vascular rings is qualitatively similar at $12-24 \mathrm{~h}$ and $14 \mathrm{~d}$ of age, as demonstrated by preliminary (unpublished) concentration-response curves. In these curves, 62.5 $\mathrm{mM} \mathrm{KCl}$ produced $75-85 \%$ of the maximal contraction induced by $125 \mathrm{mM}$ $\mathrm{KCl}$.

Cumulative concentration $(0.1 \mathrm{nM}-10 \mu \mathrm{M})$ response curves were constructed for 8-iso-PGE 1,8 -iso-PGE 2,8 -iso-PGF ${ }_{1 \alpha}, 8$-iso-PGF $1 \beta, 8$-iso-PGF $2 \alpha$, 8-iso-PGF ${ }_{2 \beta}$, and the $\mathrm{TXA}_{2}$ mimetic U46619. In some experiments, the vascular effects of isoprostanes and U46619 were tested in endotheliumdenuded arteries or in the presence of the TXA 2 receptor (TP) antagonist SQ $29,548(10 \mathrm{nM}-0.1 \mu \mathrm{M})$, the COX inhibitor indomethacin $(10 \mu \mathrm{M})$, the tyrosine kinase inhibitor genistein $(0.1 \mathrm{mM})$, the protein PKC inhibitor chelerythrine $(10 \mu \mathrm{M})$, the Rho kinase inhibitors Y $27632(10 \mu \mathrm{M})$ and hydroxyfasudil $(10 \mu \mathrm{M})$, the mitogen-activated protein kinase kinase inhibitor PD $98059(50 \mu \mathrm{M})$, and the p38-kinase inhibitor SB $203580(30 \mu \mathrm{M})$.

Drugs. Isoprostanes and U46619 (9,11-dideoxy- $11 \alpha, 9 \alpha$-epoxymethanoprostaglandin $\mathrm{F}_{2 \alpha}$ methyl acetate solution) were purchased from Cayman Chemical (Ann Arbor, MI). Y27632 was obtained from Tocris (Ellisville, MO) and hydroxyfasudil from Asahi Chemical (Tokyo, Japan). All other chemicals were obtained from Sigma Chemical Co. (St. Louis, MO). Isoprostanes, genistein, chelerythrine, PD 98059, and SB 203580 were dissolved initially in DMSO. Indomethacin and Y 27632 were dissolved initially in ethanol. All other chemicals were dissolved initially in distilled deionized water. The maximal bath concentration of DMSO and ethanol did not exceed $0.1 \%$, which was found to have no effect on mechanical activity.

Analysis of data. Results are expressed as mean \pm SEM and $n$ reflects the number of animals. The contractile responses were expressed as absolute values ( $\mathrm{g}$ ) or were standardized relative to responses to $62.5 \mathrm{mM} \mathrm{KCl}$. The potency of each isoprostane, EC50, was interpolated from the individual concentration-effect curves. However, the EC50 value for the majority of the isoprostanes was not determined, as the responses did not appear to be maximal at the highest concentration tested $(10 \mu \mathrm{M})$. The efficacy was defined as the maximum vasoconstriction (Emax) achieved with each isoprostane. Differences between mean values were assessed by one-way ANOVA followed by Bonferroni posthoc $t$ test. Differences were considered significant at a $p<0.05$.

\section{RESULTS}

Contractile effects of isoprostanes in porcine pulmonary and mesenteric vessels. Isoprostanes produced concentrationdependent contractions of 12- to 24-old and 2-wk-old piglet $\mathrm{PA}, \mathrm{PV}$, and MA with magnitudes up to 1.5- to 2-fold greater than the responses to $62 \mathrm{mM} \mathrm{KCl}$ but they showed, in general, markedly lower potency and efficacy than the TP receptor agonist U46619 (Figs. 1-3 and Table 1).

In PA (Fig. 1), 8-iso-PGE 2 appeared to be the most potent of the isoprostanes (Fig. 1B, Table 1). When constructing the cumulative concentration-response curve, addition of the highest concentrations $(>1 \mu \mathrm{M})$ of 8 -iso-PGE ${ }_{2}$ consistently reduced the vessel tone in $\mathrm{PA}$ and this effect was more marked in the 2-wk-old animals (Fig. 1B). 8-iso- $\mathrm{PGF}_{2 \alpha}$ was the most efficacious of the isoprostanes (Fig. 1D). However, the responses did not appear to be maximal at the highest concentration tested $(10 \mu \mathrm{M})$ and the detectable threshold concentration for the constrictor effects of 8 -iso- $\mathrm{PGF}_{2 \alpha}$ was relatively high $(\sim 0.1 \mu \mathrm{M})$. 8-iso-PGF ${ }_{1 \alpha}$ and 8-iso-PGF $1 \beta$ had little or no contractile effect on the 2-wk-old PA but produced a potent constriction on the neonatal PA (Fig. $1 C$ and $E$ ). In addition, 


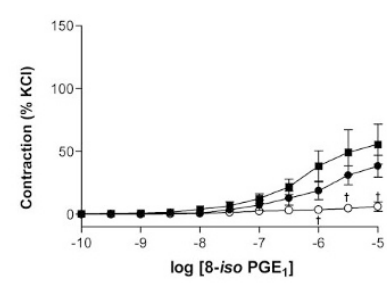

C
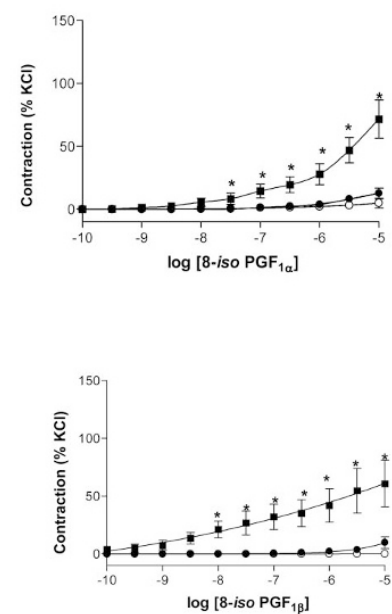

G

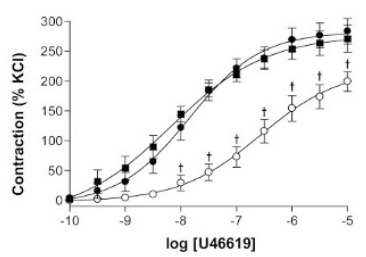

B

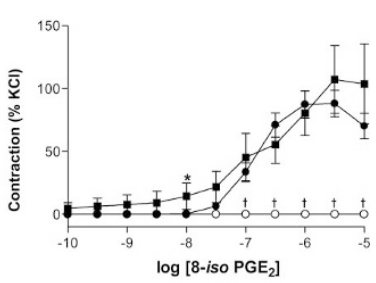

D

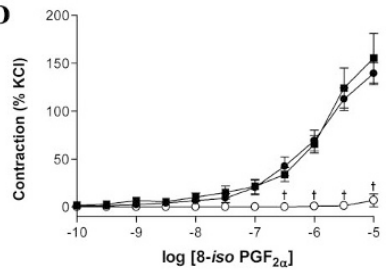

F

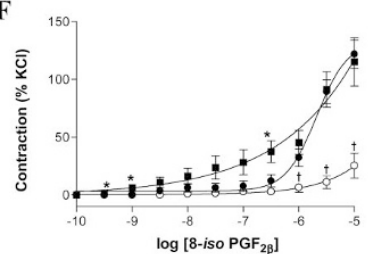

H

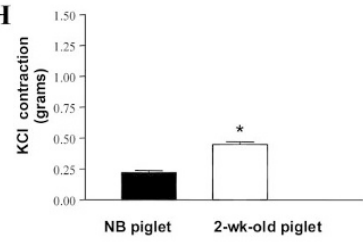

Figure 1. Isoprostane-evoked contractions in 12- to 24-h-old ( squares) and 2-wk-old (circles) piglet pulmonary arteries. Mean concentration-response relationships obtained in response to cumulative addition of 8-iso-PGE ${ }_{1}(A)$, 8-iso-PGE ${ }_{2}(B), 8$-iso- $\mathrm{PGF}_{1 \alpha}(C), 8$-iso- $\mathrm{PGF}_{2 \alpha}(D)$, 8-iso-PGF $1 \beta$ (E), and 8 -iso- $\mathrm{PGF}_{2 \beta}(F)$. Contractions evoked in response to the $\mathrm{TXA}_{2}$ mimetic $\mathrm{U} 46619(G)$ and $62.5 \mathrm{mM} \mathrm{KCl}(H)$ are also represented. Responses are expressed as a percentage of the response to $62.5 \mathrm{mM} \mathrm{KCl}$ evoked in each tissue at the beginning of the study. Open symbols represent isoprostaneevoked contraction in the presence of the TP receptor antagonist SQ 29,548 (10 $\mathrm{nM})$. Each point represents the mean \pm SEM of $6-24$ animals. ${ }^{*} p<0.0512-$ to 24-h-old vs 2-wk-old. $\dagger p<0.05$ vs control.

the contractions induced by 8 -iso- $\mathrm{PGE}_{2}$ (only one point) and 8 -iso-PGF ${ }_{2 \beta}$ were, at some of the concentrations tested, significantly higher in neonatal than in 2-wk-old PA (Fig. $1 B$ and $F$ ). Significant age-related changes were not observed for the PA contractions induced by 8 -iso- $\mathrm{PGE}_{1}, 8$-iso- $\mathrm{PGF}_{2 \alpha}$, and U46619 (Fig. 1, Table 1).

In PV (Fig. 2), 8-iso- $\mathrm{PGE}_{2}$ was the most potent and efficacious of the isoprostanes, being, in terms of efficacy (but not of potency), comparable with U46619 in the 12- to 24-h-old animals (Fig. 2B, Table 1). The efficacy of 8-iso$\mathrm{PGF}_{2 \alpha}$ (Fig. $2 D$ ) in neonatal $\mathrm{PV}$ was also comparable to U46619. When comparing isoprostane-evoked contractions in 12- to 24-h-old and 2-wk-old PV, a clear ontogenic pattern was not observed. However, for some particular concentrations, 8 -iso- $\mathrm{PGE}_{2}$ and 8 -iso- $\mathrm{PGF}_{1 \alpha}$ produced a higher level of contraction in the neonatal PV (Fig. $2 B$ and

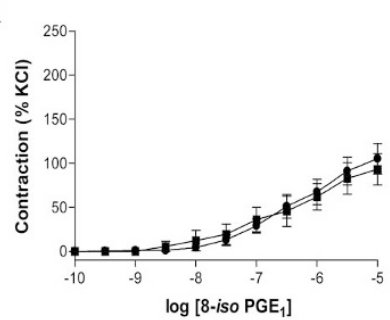

C

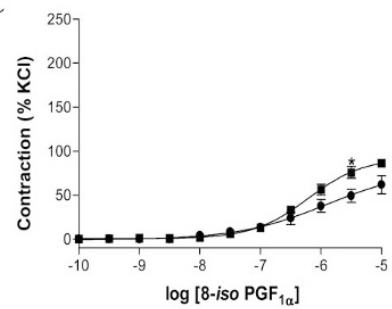

$\mathbf{E}$

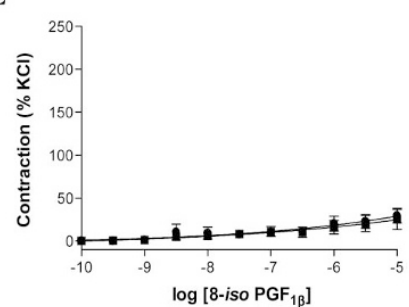

G

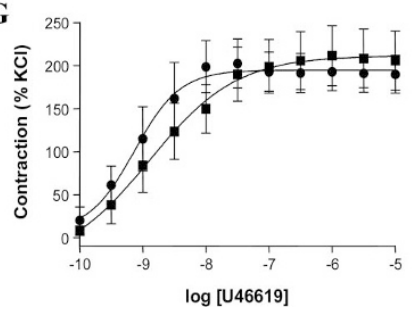

B

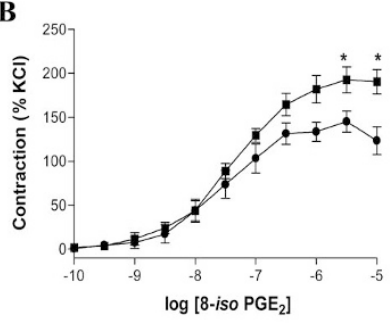

D

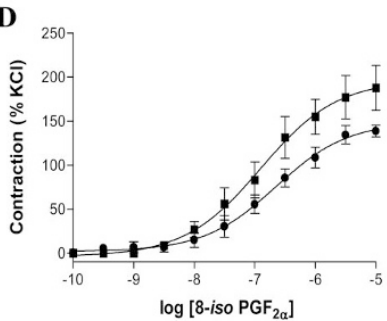

F

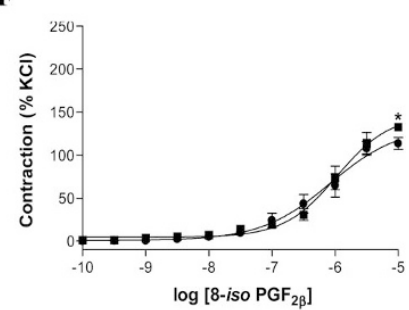

H

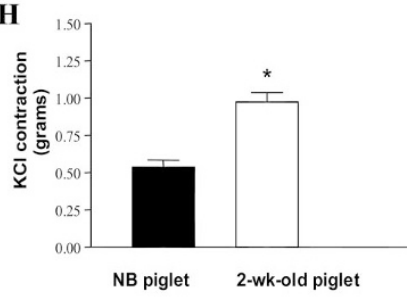

Figure 2. Isoprostane-evoked contractions in 12- to 24-h-old (squares) and 2 -wk-old (circles) piglet pulmonary veins. Mean concentration-response relationships obtained in response to cumulative addition of 8 -iso- $\mathrm{PGE}_{1}(A)$, 8-iso-PGE $2(B)$, 8-iso-PGF ${ }_{1 \alpha}(C)$, 8-iso- $\mathrm{PGF}_{2 \alpha}(D)$, 8-iso-PGF $1 \beta$ (E), and 8 -iso-PGF $\mathrm{PG}_{2 \beta}(F)$. Contractions evoked in response to the $\mathrm{TXA}_{2}$ mimetic $\mathrm{U} 46619(G)$ and $62.5 \mathrm{mM} \mathrm{KCl}(H)$ are also represented. Responses are expressed as a percentage of the response to $62.5 \mathrm{mM} \mathrm{KCl}$ evoked in each tissue at the beginning of the study. Each point represents the mean \pm SEM of 5-8 animals. $* p<0.0512$ - to 24-h-old $v s$ 2-wk-old.

C). As occurred with the PA, addition of high concentrations $(>10 \mu \mathrm{M})$ of 8 -iso- $\mathrm{PGE}_{2}$ consistently reduced tone in PV and this effect was more marked in the 2-wk-old animals (Fig. 2B).

In MA (Fig. 3), the response to isoprostanes demonstrated a high degree of variability. In spite of that, we observed that 8 -iso-PGE ${ }_{2}$ was the most potent and efficacious of the isoprostanes, being, in terms of efficacy (but not of potency), comparable with U46619 in the 12- to 24-h-old animals (Fig. 3B, Table 1). As shown in Figure 3, the relaxation induced by high doses of 8-iso-PGE 2 in PA and PV was not observed in MA (the maximal concentration tested was $10 \mu \mathrm{M}$ ). 8-iso- $\mathrm{PGE}_{2}$, 8-iso-PGF ${ }_{1 \alpha}, 8$-iso-PGF ${ }_{2 \alpha}$, and 8-iso- $\mathrm{PGF}_{2 \beta}$ produced higher contractions in neonatal MA than in the corresponding 2-wk- 
A

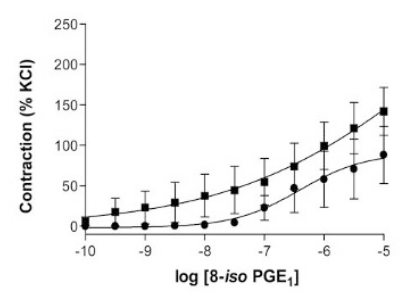

C

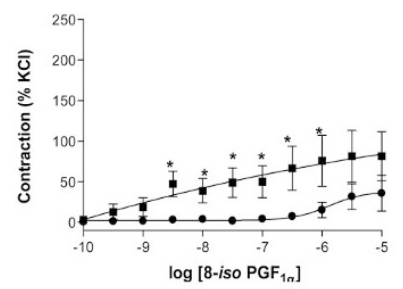

$\mathbf{E}$
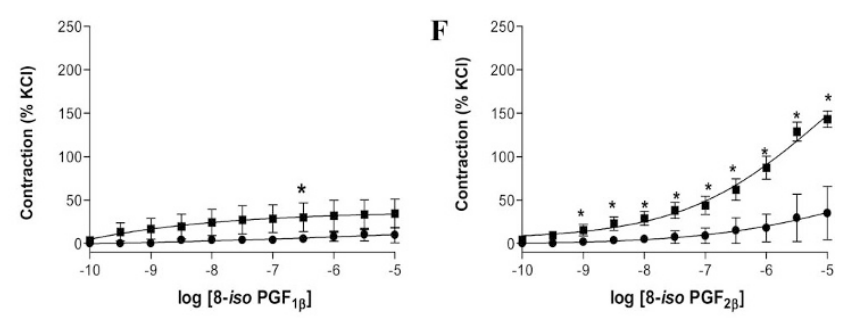

G

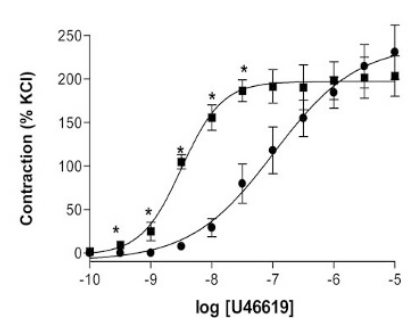

H

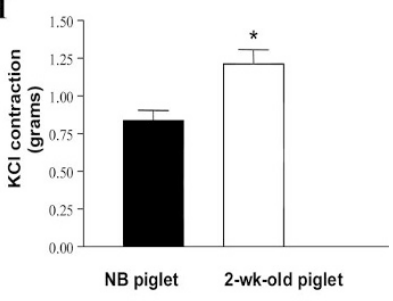

Figure 3. Isoprostane-evoked contractions in 12- to 24-h-old (squares) and 2-wk-old (circles) piglet mesenteric arteries. Mean concentration-response relationships obtained in response to cumulative addition of 8 -iso- $\mathrm{PGE}_{1}(A)$, 8-iso-PGE $2(B), 8$-iso-PGF - $_{1 \alpha}(C), 8$-iso-PGF $2 \alpha(D), 8$-iso-PGF ${ }_{1 \beta}(E)$, and 8-iso-PGF ${ }_{2 \beta}(F)$. Contractions evoked in response to the $\mathrm{TXA}_{2}$ mimetic $\mathrm{U} 46619(G)$ and $62.5 \mathrm{mM} \mathrm{KCl}(H)$ are also represented. Responses are expressed as a percentage of the response to $62.5 \mathrm{mM} \mathrm{KCl}$ evoked in each tissue at the beginning of the study. Each point represents the mean \pm SEM of 5-9 animals. $* p<0.05$ 12- to 24-h-old vs 2-wk-old.

old vessels (Fig. 3, Table 1). Sensitivity to U46619 also decreased with postnatal age (Fig. $3 G$, Table 1).

Involvement of TP receptors in mediating isoprostane contractions. We examined the effect of the TP receptor antagonist SQ 29,548 on isoprostane- and U46619-mediated contractions in piglet pulmonary and MA and PV. When 2-wk-old PA were exposed to SQ 29,548 (10 $\mathrm{nM})$, the contractile responses to isoprostanes and U46619 were markedly reduced or even abolished (Fig. 1). In another group of experiments, tissues were first preconstricted with isoprostanes or U46619 at a concentration of $10 \mu \mathrm{M}$, then challenged with SQ 29,5480 (0.1 $\mu \mathrm{M})$. We observed that isoprostane- and U46619-induced contractions of 12- to 24-h-old and 2-wk-old PA, PV, and MA were significantly reversed or completely abolished by SQ
29,548 (not shown). In contrast, SQ 29,548 had no remarkable effect on the contractions induced by endothelin-1 $(0.1 \mu \mathrm{M})$ or $\mathrm{KCl}(62.5 \mathrm{mM})$.

Characterization of underlying signalling pathways. The contribution of various signalling pathways to 8 -iso- $\mathrm{PGE}_{2}$, 8-iso- $\mathrm{PGF}_{2 \alpha^{-}}, 8$-iso- $\mathrm{PGF}_{2 \beta^{-}}$, and U46619-evoked contractions were examined pharmacologically in the 2-wk-old PA. 8-iso$\mathrm{PGE}_{2}, 8$-iso-PGF ${ }_{2 \alpha}, 8$-iso- $\mathrm{PGF}_{2 \beta}$, and $\mathrm{U} 46619$ were tested because they produced the highest level of contraction. Endothelium removal and COX inhibition did not significantly affect isoprostane- or U46619-induced contractions (Figs. 4-7). In another group of experiments, 2-wk-old PA were exposed to various kinase inhibitors for 20-30 min before the concentration-response curves to 8-iso- $\mathrm{PGE}_{2}, 8$-iso- $\mathrm{PGF}_{2 \alpha}$, 8 -iso-PGF $2 \beta$, and U46619 were carried out. Contractions to isoprostanes and $\mathrm{U} 46619$ were unaffected by the PKC inhibitor chelerythrine, the mitogen-activated protein kinase kinase PD 98059, or the p38-kinase inhibitor SB 203580 (Figs. 4-7) but were markedly reduced or abolished by the tyrosine kinase inhibitor genistein or the Rho kinase inhibitors Y 27632 and hydroxyfasudil (Figs. 4-7).

\section{DISCUSSION}

We have examined the effects of a wide range of isoprostanes in pulmonary and mesenteric blood vessels from 12- to 24-h-old and 2-wk-old piglets. We found several E-ring (8-iso$\mathrm{PGE}_{1}$ and 8-iso- $\mathrm{PGE}_{2}$ ) and F-ring (8-iso-PGF ${ }_{1 \alpha}, 8$-iso-PGF ${ }_{1 \beta}$, 8-iso-PGF ${ }_{2 \alpha}$, and 8-iso- $\mathrm{PGF}_{2 \beta}$ ) isoprostanes to increase tone in these vascular smooth muscles to varying degrees. Interestingly, some of the isoprostanes induced higher contractile responses in neonatal than in 2-wk-old vessels. Either in PA, $\mathrm{PV}$, or MA isoprostane-induced contraction was markedly reduced in the presence of the thromboxane TP receptor antagonist SQ 29,548, indicating that isoprostane-evoked responses involve primarily these receptors. This leads to the suggestion that isoprostanes may act as an alternative ligand for TP receptors in addition to $\mathrm{TXA}_{2}$ itself. Although high concentrations of isoprostanes (in the micromolar range) were required to induce significant vascular contraction, high local concentrations of some of these compounds are found in clinical situations of oxidative injury $(22,23)$. Thus, it is likely that incidental activation of the TP receptors by isoprostanes may indeed contribute to and exacerbate the pathology associated with oxidative injury in the neonatal period.

Isoprostanes and pulmonary vessels. During the transition from fetal to postnatal life, dramatic changes in the pulmonary circulation take place, characterized by a marked decrease in pulmonary vascular resistance within minutes from birth. A second postnatal phase of pulmonary vascular resistance reduction takes place over the first weeks of extrauterine life (24). Several age-related changes on pulmonary vascular reactivity have been characterized during this second phase of pulmonary vascular resistance reduction (14-16). However, this study and another (25) showed that the responses of pulmonary vessels to U46619 did not change with postnatal age. Because U46619 is a selective agonist of TP receptors, these results suggest that there are no developmental changes 
Table 1. Parameters of the concentration-response curves reflecting the efficacy and potency (Emax and EC50, respectively) of 8-iso-PGE 2 and U46619 in pulmonary and mesenteric vasculature of 12- to 24-h-old (NB) and 2-wk-old (2 wk) piglets

\begin{tabular}{|c|c|c|c|c|c|c|c|}
\hline & & \multicolumn{3}{|c|}{ 8-iso-PGE ${ }_{2}$} & \multicolumn{3}{|c|}{ U46619 } \\
\hline & & $\operatorname{Emax}(\% \mathrm{KCl})$ & $\log \mathrm{EC} 50$ & $n$ & $\operatorname{Emax}(\% \mathrm{KCl})$ & $\log \mathrm{EC} 50$ & $n$ \\
\hline Pulmonary artery & NB & $114.46 \pm 30.79$ & $-6.58 \pm 0.17$ & 7 & $269.42 \pm 26.09$ & $-8.06 \pm 0.13$ & 9 \\
\hline \multirow[t]{2}{*}{ Pulmonary vein } & NB & $198.77 \pm 14.40^{*}$ & $-7.44 \pm 0.12$ & 6 & $216.25 \pm 35.71$ & $-9.19 \pm 0.63$ & 6 \\
\hline & $2 \mathrm{wk}$ & $144.77 \pm 11.32$ & $-7.61 \pm 0.22$ & 8 & $193.96 \pm 22.28$ & $-8.45 \pm 0.58$ & 5 \\
\hline Mesenteric artery & NB & $211.53 \pm 22.26$ & $-7.26 \pm 0.46^{* *}$ & 6 & $203.38 \pm 13.16$ & $-8.29 \pm 0.09 * *$ & 7 \\
\hline
\end{tabular}

Contractions are expressed as the percentage of the response to $62.5 \mathrm{mM} \mathrm{KCl}$ evoked in each tissue at the beginning of the study.

$*, * * p<0.05,0.01$ 12- to 24-h-old vs 2-wk-old.
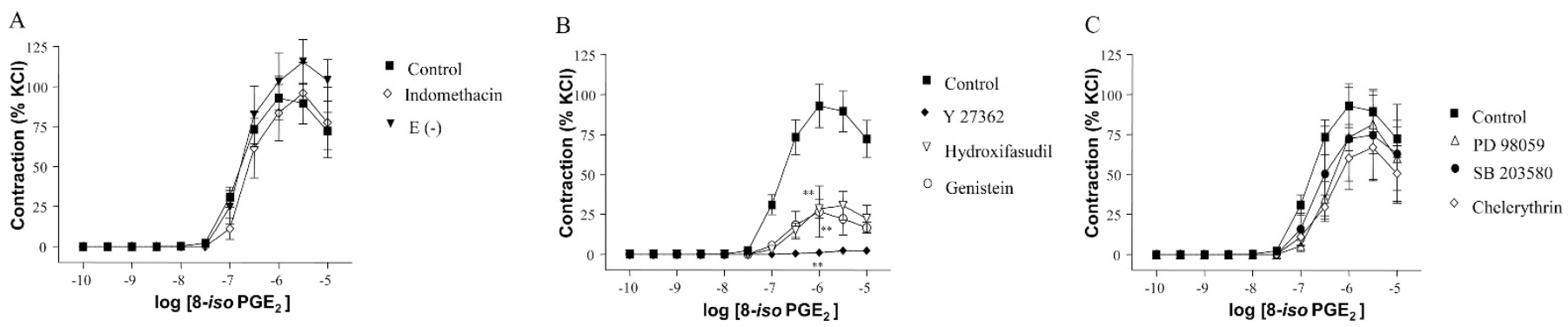

Figure 4. Mean dose-response relationship for 8 -iso- $\mathrm{PGE}_{2}$ in 2-wk-old piglet pulmonary artery, obtained in the presence and absence of the following: endothelium, the cyclooxygenase inhibitor indomethacin $(10 \mu \mathrm{M})$, the Rho kinase inhibitors Y $27632(10 \mu \mathrm{M})$ and hydroxyfasudil $(10 \mu \mathrm{M})$, the tyrosine kinase inhibitor genistein $(0.1 \mathrm{mM})$, the mitogen-activated protein kinase kinase inhibitor PD $98059(50 \mu \mathrm{M})$, the p38-kinase inhibitor SB $203580(30 \mu \mathrm{M})$, and the protein kinase $\mathrm{C}$ inhibitor chelerythrine $(10 \mu \mathrm{M})$. Each point represents the mean \pm SEM of 5-6 animals. **p $<0.01 v s$ control. Only levels of statistical significance for the highest difference are shown.
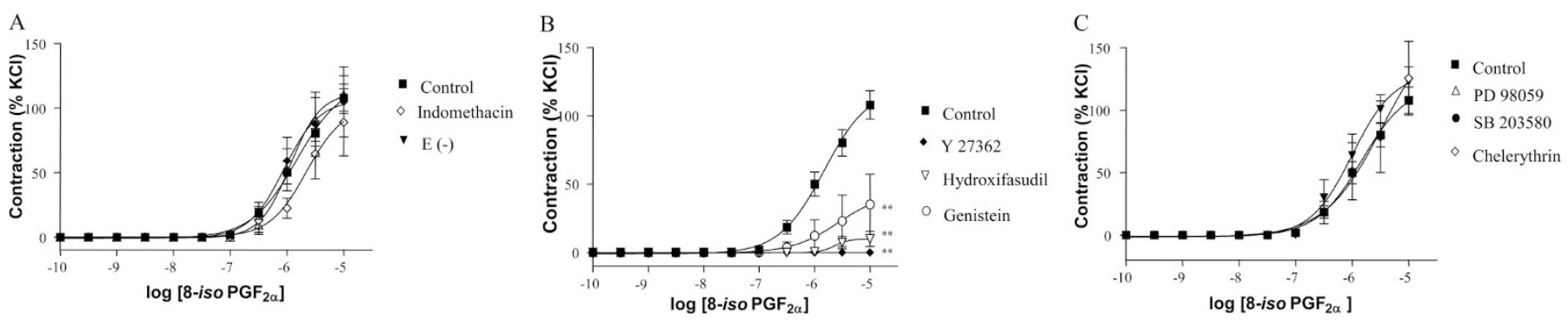

Figure 5. Mean dose-response relationship for 8 -iso- $\mathrm{PGF}_{2 \alpha}$ in 2-wk-old piglet pulmonary artery, obtained in the presence and absence of the following: endothelium, the cyclooxygenase inhibitor indomethacin $(10 \mu \mathrm{M})$, the Rho kinase inhibitors Y $27632(10 \mu \mathrm{M})$ and hydroxyfasudil (10 $\mu \mathrm{M})$, the tyrosine kinase inhibitor genistein $(0.1 \mathrm{mM})$, the mitogen-activated protein kinase kinase inhibitor PD $98059(50 \mu \mathrm{M})$, the p38-kinase inhibitor SB $203580(30 \mu \mathrm{M})$, and the protein kinase $\mathrm{C}$ inhibitor chelerythrine $(10 \mu \mathrm{M})$. Each point represents the mean \pm SEM of $5-6$ animals. $* * p<0.01 v s$ control. Only levels of statistical significance for the highest difference are shown.

in TP-receptor activity. In contrast, we found age-related differences on isoprostane-evoked responses in PA and veins, i.e. a reduction with postnatal age in the contractile responses of $\mathrm{PA}$ and/or PV to 8-iso-PGF ${ }_{1 \alpha}, 8$-iso-PGF $1 \beta, 8$-iso-PGF ${ }_{1 \beta}$, and 8 -iso-PGE ${ }_{2}$. Therefore, age-related decreases in pulmonary vascular sensitivity to isoprostanes appear to be a specific phenomenon for mild stimulation of TP receptor with these compounds more than a general reduction in the contractile response of the pulmonary vessels with age.

In a previous study in 2-wk-old piglets, Truog et al. (20) observed that 8 -iso- $\mathrm{PGF}_{2 \alpha}$ induced, in a dose-dependent manner, marked pulmonary vasoconstriction transduced through the TP receptor. However, when compared with U46619, 8 -iso-PGF ${ }_{2 \alpha}$ was less potent by approximately one order of magnitude (20). Janssen and Tazzeo (21) and Tazzeo et al. (26) examined the responses of adult porcine $\mathrm{PA}$ and veins to 8-iso-PGE 1,8 -iso-PGE 2,8 -iso-PGF ${ }_{1 \alpha}, 8$-iso-PGF ${ }_{2 \alpha}$, and 8-iso-
$\mathrm{PGF}_{2 \beta}$, finding that 8 -iso-PGE 2 was the most potent and efficacious in both PA and veins. However, isoprostanes exerted, in adult pulmonary vessels, maximal contractions that were $50-90 \%$ of the response to $60 \mathrm{mM} \mathrm{KCl}$, whereas the contractions that we describe in 12- to 24-h-old and 2-wk-old tissues were as much as $150-200 \%$ of the response to $\mathrm{KCl}$. Therefore, the age-related decrease in isoprostane-evoked contractions, which we have found by comparing neonatal and 2-wk-old animals, seems to be augmented in adult vessels. Another point of interest is that some of the F-ring isoprostanes, such as 8-iso- $\mathrm{PGF}_{2 \alpha}$ and 8-iso- $\mathrm{PGF}_{2 \beta}$, produced, in our experiments, levels of contraction that are comparable with those induced by the E-ring isoprostanes. In contrast, in the porcine adult pulmonary vessels, F-ring isoprostanes induced markedly weaker contractions than E-ring isoprostanes $(21,26)$. Finally, Janssen and Tazzeo (21) observed that, although the contractions induced in adult porcine PA and PV by 

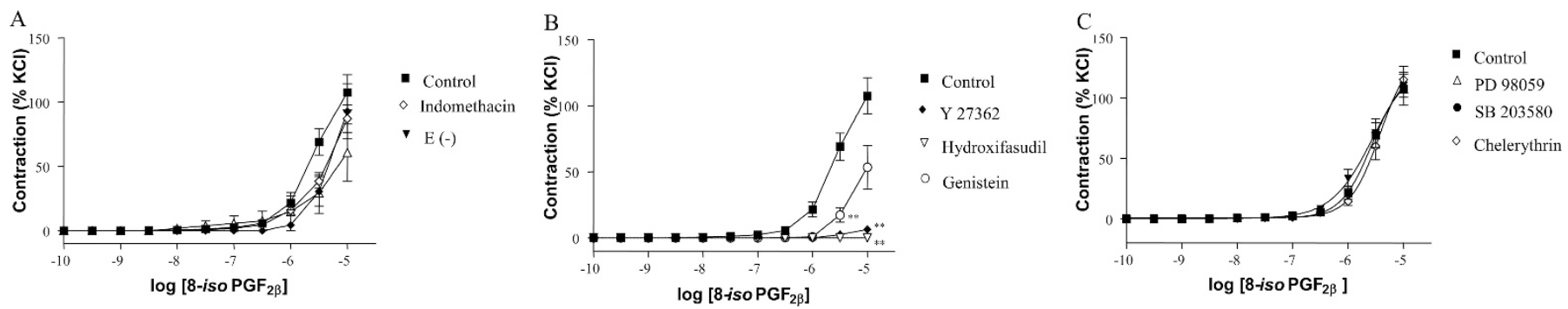

Figure 6. Mean dose-response relationship for 8 -iso- $\mathrm{PGF}_{2 \beta}$ in 2 -wk-old piglet pulmonary artery, obtained in the presence and absence of the following: endothelium, the cyclooxygenase inhibitor indomethacin $(10 \mu \mathrm{M})$, the Rho kinase inhibitors $\mathrm{Y} 27632(10 \mu \mathrm{M})$ and hydroxyfasudil (10 $\mu \mathrm{M})$, the tyrosine kinase inhibitor genistein $(0.1 \mathrm{mM})$, the mitogen-activated protein kinase kinase inhibitor PD $98059(50 \mu \mathrm{M})$, the p38-kinase inhibitor SB $203580(30 \mu \mathrm{M})$, and the protein kinase $\mathrm{C}$ inhibitor chelerythrine $(10 \mu \mathrm{M})$. Each point represents the mean \pm SEM of $5-6$ animals. $* * p<0.01 v s$ control. Only levels of statistical significance for the highest difference are shown.
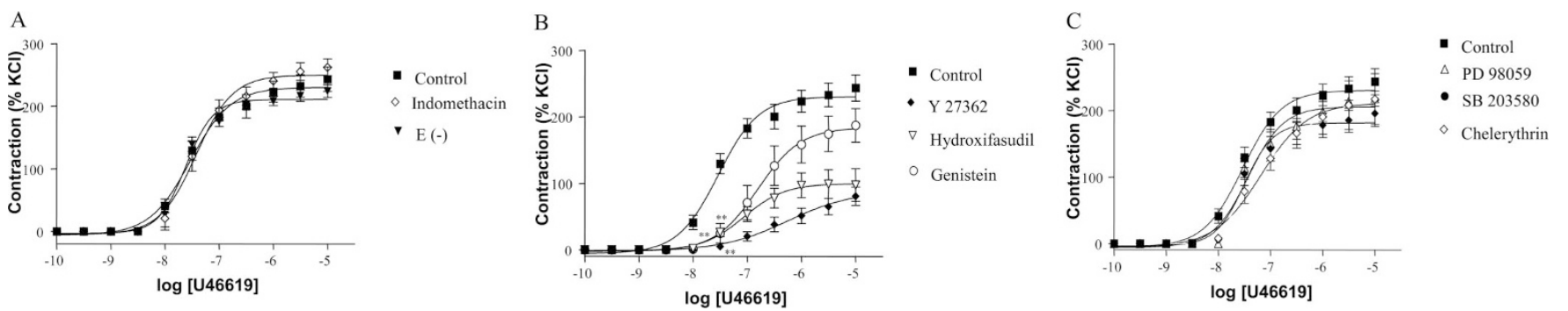

Figure 7. Mean dose-response relationship for U46619 in 2-wk-old piglet pulmonary artery, obtained in the presence and absence of the following: endothelium, the cyclooxygenase inhibitor indomethacin $(10 \mu \mathrm{M})$, the Rho kinase inhibitors $\mathrm{Y} 27632(10 \mu \mathrm{M})$ and hydroxyfasudil $(10 \mu \mathrm{M})$, the tyrosine kinase inhibitor genistein $(0.1 \mathrm{mM})$, the mitogen-activated protein kinase kinase inhibitor PD $98059(50 \mu \mathrm{M})$, the p38-kinase inhibitor SB $203580(30 \mu \mathrm{M})$, and the protein kinase $\mathrm{C}$ inhibitor chelerythrine $(10 \mu \mathrm{M})$. Each point represents the mean \pm SEM of 5-6 animals. ${ }^{* *} p<0.01 v s$ control. Only levels of statistical significance for the highest difference are shown.

8-iso-PGE 1,8 -iso- $\mathrm{PGF}_{1 \alpha}, 8$-iso- $\mathrm{PGF}_{2 \alpha}$, and 8-iso- $\mathrm{PGF}_{2 \beta}$ were essentially completely prevented by TP receptor blockade, 8-iso- $\mathrm{PGE}_{2}$ was able to evoke substantial contraction of PV in the maintained presence of TP receptor blockade. Moreover, their data suggest that, in the adult porcine PV, 8-iso- $\mathrm{PGE}_{2}$ can also act upon another type of excitatory receptor, likely $\mathrm{EP}_{3}$ receptors or a unique isoprostane receptor (21). Our data do not allow us to speculate on the presence of these putative isoprostane receptors. However, we found 8-iso- $\mathrm{PGE}_{2}$ evoked contractions of PV, PA, and MA to be equally highly sensitive to the TP-receptor blocker SQ 29,548.

8 -iso- $\mathrm{PGF}_{2 \alpha}$ is the isoprostane upon which most previous studies focused. In fact, the only previous study evaluating age-related changes in the vascular actions of isoprostanes described the effects of 8-iso-PGF ${ }_{2 \alpha}$ in intralobar PA segments of 1- and 2-wk-old rats, compared with adults (9). Belik et al. (9) demonstrated that force developed by the rat PA in response to 8-iso-PGF ${ }_{2 \alpha}$ increased with postnatal age. However, the lesser force development of the newborn pulmonary arterial muscle during 8-iso- $\mathrm{PGF}_{2 \alpha}$ stimulation reflected the decreased force potential of this tissue in response to a number of stimuli, including the TxA $\mathrm{A}_{2}$ analog U46619 (9). In contrast, we have not observed developmental changes on the response to U46619 in porcine pulmonary vessels. Interestingly, when PA were stimulated with U46619, Belik et al. (9) observed an 8 -iso-PGF ${ }_{2 \alpha}$-induced relaxation in the adult and a marked dose-dependent contraction in the 1-wk-old rat. This contractile effect of 8-iso- $\mathrm{PGF}_{2 \alpha}$ was abolished by endothelium removal and NO synthase inhibition and was markedly attenu- ated by COX inhibition (9). In contrast, we did not observe any significant alteration of 8-iso-PGF ${ }_{2 \alpha}$-induced contraction when endothelium was removed or the COX inhibitor indomethacin was present. Moreover, during stimulation of either neonatal or 2-wk-old PA with U46619 $(0.1 \mu \mathrm{M})$, we did not observe additional contractions produced by any of the six isoprostanes tested in the present work (27). Therefore, the vascular actions of isoprostanes seem to be markedly species-dependent. This fact limits the extrapolation of our results to the human newborn. In fact, Tazzeo et al. (26) compared the responses to isoprostanes of human and porcine PA and found a higher efficacy of these compounds in the human tissues. However, the underlying signaling pathways of isoprostane-induced contraction were similar in both species.

Using pharmacological tools, we sought to characterize the signaling pathways underlying the PA vasoconstrictor responses to 8 -iso- $\mathrm{PGE}_{2}, 8$-iso- $\mathrm{PGF}_{2 \alpha}, 8$-iso- $\mathrm{PGF}_{2 \beta}$, and U46619. The PKC inhibitor chelerythrine had no effect on isoprostane- or U46619-induced contractions. In contrast, it has been recently reported that an atypical isoform of PKC (PKC $\zeta)$ plays a key role in U46619-induced contraction in rat PA (28). It might be argued that chelerythrine is a poor inhibitor of this isoform (29). However, calphostin C or the $\mathrm{PKC} \zeta$ pseudosubstrate peptide, which are effective inhibitors of $\operatorname{PKC} \zeta$, were also without effect on the vasoconstriction induced by U46619 in 2-wk-old piglet PA (unpublished experiments) indicating interspecies differences in the signal transduction pathways. 
8-iso-PGE $2^{-}$, 8-iso-PGF $2 \alpha^{-}$, 8-iso- $\mathrm{PGF}_{2 \beta^{-}}$, and U46619evoked pulmonary artery contractions were unaffected by inhibitors of the mitogen-activated protein kinase kinase (PD 98059) or the p38-kinase (SB 203580), but markedly reduced by the nonspecific tyrosine kinase inhibitor genistein. Tyrosine kinases are known to activate several other kinases (7). We found that two agents highly selective for Rho-kinase (Y 27632 and hydroxyfasudil) also inhibited isoprostane- and U46619mediated contractions. Therefore, the excitatory effects of 8-iso-PGE 2,8 -iso- $\mathrm{PGF}_{2 \alpha}, 8$-iso-PGF $2 \beta$, and U46619 in 2-wkold PA appear to be mediated by TP receptors and their signaling pathways involve tyrosine kinases(s) and Rhokinase. Similar signaling pathways of isoprostane-evoked constriction have been reported in human and canine pulmonary vasculature (7). Intracellular signaling via the small GTPbinding protein RhoA and its downstream effector Rho-kinase plays a role in regulating diverse cellular functions, including vascular smooth muscle contraction (30). Maturational changes in the RhoA/Rho-kinase pathway have been very recently described in piglet pulmonary arteries (30). The putative role of RhoA/Rho-kinase maturation in age-related changes in isoprostane-evoked responses remains to be investigated.

Pulmonary veins are exposed to higher oxygen concentrations than PA, but it seems that this fact does not imply a higher activity of antioxidant defenses $(15,31)$. Thus, PV are presumably exposed to higher oxidant conditions and, consequently, to higher formation of isoprostanes. In addition, PV are the major site of action of a number of vasoactive factors in different animal species and at different ages $(14,32,33)$. In the present work, we found porcine PV to exhibit a profound vasoconstrictor response to several isoprostanes. Certain isoprostanes (8-iso-PGE 1 , 8-iso-PGE ${ }_{2}$ ) were more potent vasoconstrictors in PV than in PA. Moreover, at high concentrations $(1-10 \mu \mathrm{M})$, contractions produced by 8 -iso- $\mathrm{PGE}_{2}$ and 8-iso-PGF ${ }_{2 \alpha}$ were similar in magnitude than U46619-evoked contractions. In addition, we have observed an age-related decrease of the responses induced by 8 -iso- $\mathrm{PGE}_{2}$ and 8-iso$\mathrm{PGF}_{1 \alpha}$ (only one point). Previous studies have evaluated the response to isoprostanes of adult human (7), canine (7), and porcine (21) PV. Human PV responded to E-ring and F-ring isoprostanes but to a lesser extent than human PA (7). The canine PA was essentially unresponsive to isoprostanes, whereas the PV exhibited a marked stimulatory response to both E- and F-ring compounds (7). Finally, in the adult porcine pulmonary vessels, the differences between arteries and veins concerning isoprostane-induced contractions (21) are not so marked as those presently described in neonatal vessels.

Isoprostanes and mesenteric arteries. The fetal intestine is functionally dormant and has a high vascular resistance, most likely because its oxidative demands are significantly low $(18,34)$. Vascular resistance in the intestinal bed drops dramatically at birth, when increased intestinal function demands an enhanced oxygen delivery (18). This transition is accompanied by dramatic functional changes in mesenteric vascular reactivity, as occurs in the other dormant fetal organ, the lung (18). NO, endothelin-1, and myogenic responses are the three determinant factors for vascular control in 1-d-old porcine small
MA $(18,35)$. In older subjects, however, these vessels are primarily passive in nature and fail to demonstrate significant diameter change in response to NO synthase inhibitors, blockade of endothelin receptors, or changes of pressure or flow rate (18). In the present work, we observed a significant postnatal decrease in isoprostane-evoked contraction of rings from the distal portion of the MA trunk. However, and in contrast with the pulmonary vessels, the sensitivity of the MA to U46619 also decreased with age. Vascular reactivity data obtained in larger arteries are difficult to extrapolate to small resistance arteries. However, we speculate that this age-related reduction in the response to TP-receptor stimulation, by either isoprostanes or $\mathrm{TXA}_{2}$, may play a role in the postnatal reduction of mesenteric vascular resistance.

Conclusion. An increasing body of evidence seems to indicate that free radicals are involved in several neonatal disease processes such as chronic lung disease, retinopathy of prematurity, necrotizing enterocolitis, and periventricular leukomalacia $(12,36)$. There are also accumulating data implying the involvement of reactive oxygen species and oxidative stress in signal transduction of numerous biologic processes, including control of newborn transitional circulation $(15,16,37)$. This type of cell signalling consistently implies the additional involvement of other bioactive molecules, such as isoprostanes, that stem from reactive oxygen species reaction with cell membrane lipids. In the present work, we describe for the first time the effects of a wide range of E-ring and F-ring isoprostanes in 12- to 24-h-old and 2-wk-old porcine pulmonary and mesenteric vasculature. We found that isoprostanes evoked vasoconstriction via an action on TP receptor and that the response to some of the isoprostanes decreased with postnatal age. Although information obtained in conduit arteries should be cautiously extrapolated to resistance vessels and to in vivo situations, we speculate that age-related changes in isoprostane activity may have implications for the perinatal circulatory transition. Whether neonatal pathologic conditions with increased oxidative stress result in alterations not only in isoprostane production but also in the vascular response to these compounds, remains to be investigated.

\section{REFERENCES}

1. Roberts LJ II, Morrow JD 1997 The generation and actions of isoprostanes. Biochim Biophys Acta 1345:121-135

2. Janssen LJ 2001 Isoprostanes: an overview and putative roles in pulmonary pathophysiology. Am J Physiol Lung Cell Mol Physiol 280:L1067-L1082

3. Pratico D, Lawson JA, Rokach J, FitzGerald GA 2001 The isoprostanes in biology and medicine. Trends Endocrinol Metab 12:243-247

4. Baraldi E, Ghiro L, Piovan V, Carraro S, Ciabattoni G, Barnes PJ, Montuschi P 2003 Increased exhaled 8-isoprostane in childhood asthma. Chest 124:25-31

5. Cracowski JL, Cracowski C, Bessard G, Pepin JL, Bessard J, Schwebel C, StankeLabesque F, Pison C 2001 Increased lipid peroxidation in patients with pulmonary hypertension. Am J Respir Crit Care Med 164:1038-1042

6. Crankshaw DJ, Rangachari PK 2003 Isoprostanes: more than just mere markers. Mol Cell Biochem 253:125-130

7. Janssen LJ, Premji M, Netherton S, Coruzzi J, Lu-Chao H, Cox PG 2001 Vasoconstrictor actions of isoprostanes via tyrosine kinase and Rho kinase in human and canine pulmonary vascular smooth muscles. Br J Pharmacol 132:127-134

8. Neefjes VM, Evelo CT, Baars LG, Blanco CE 1999 Erythrocyte glutathione S transferase as a marker of oxidative stress at birth. Arch Dis Child Fetal Neonatal Ed 81:F130-F133

9. Belik J, Jankov RP, Pan J, Yi M, Pace-Asciak CR, Tanswell AK 2003 Effect of 8-isoprostaglandin F2alpha on the newborn rat pulmonary arterial muscle and endothelium. J Appl Physiol 95:1979-1985

10. Qin Y, Wang CC, Kuhn H, Rathmann J, Pang CP, Rogers MS 2000 Determinants of umbilical cord arterial 8-iso-prostaglandin F2alpha concentrations. BJOG 107:973981 
11. Stier C, Schweer H, Jelinek J, Watzer B, Seyberth HW, Leonhardt A 2001 Effect of preterm formula with and without long-chain polyunsaturated fatty acids on the urinary excretion of F2-isoprostanes and 8-epi-prostaglandin F2alpha. J Pediat Gastroenterol Nutr 32:137-141

12. Ahola T, Fellman V, Kjellmer I, Raivio KO, Lapatto R 2004 Plasma 8-isoprostane is increased in preterm infants who develop bronchopulmonary dysplasia or periventricular leukomalacia. Pediatr Res 56:88-93

13. Goil S, Truog WE, Barnes C, Norberg M, Rezaiekhaligh M, Thibeault D 1998 Eight-epi-PGF2alpha: a possible marker of lipid peroxidation in term infants with severe pulmonary disease. J Pediatr 132:349-35

14. Villamor E, Perez-Vizcaino F, Cogolludo AL, Conde-Oviedo J, Zaragoza-Arnaez F, Lopez-Lopez JG, Tamargo J 2000 Relaxant effects of carbon monoxide compared with nitric oxide in pulmonary and systemic vessels of newborn piglets. Pediatr Res 48:546-553

15. Villamor E, Kessels CG, Fischer MA, Bast A, de Mey JG, Blanco CE 2003 Role of superoxide anion on basal and stimulated nitric oxide activity in neonatal piglet pulmonary vessels. Pediatr Res 54:372-381

16. Perez-Vizcaino F, Lopez-Lopez JG, Santiago R, Cogolludo A, Zaragoza-Arnaez F, Moreno L, Alonso MJ, Salaices M, Tamargo J 2002 Postnatal maturation in nitric oxide-induced pulmonary artery relaxation involving cyclooxygenase-1 activity. Am J Physiol Lung Cell Mol Physiol 283:L839-L848

17. Morecroft I, MacLean MR 1998 Developmental changes in endothelium-dependen vasodilation and the influence of superoxide anions in perinatal rabbit pulmonary arteries. Br J Pharmacol 125:1585-1593

18. Nankervis CA, Dunaway DJ, Nowicki PT 2001 Determinants of terminal mesenteric artery resistance during the first postnatal month. Am J Physiol Gastrointest Liver Physiol 280:G678-G686

19. Reber KM, Su BY, Clark KR, Pohlman DL, Miller CE, Nowicki PT2002 Developmental expression of eNOS in postnatal swine mesenteric artery. Am J Physiol Gastrointest Liver Physiol 283:G1328-G1335

20. Truog WE, Norberg M, Thibeault DW 1997 Effects of 8-epi-prostaglandin F2 alph and U46,619 on pulmonary hemodynamics in piglets. Biol Neonate 71:306-316

21. Janssen LJ, Tazzeo T 2002 Involvement of TP and EP3 receptors in vasoconstricto responses to isoprostanes in pulmonary vasculature. J Pharmacol Exp Ther 301:1060-1066

22. Patrono C, FitzGerald GA 1997 Isoprostanes: potential markers of oxidant stress in atherothrombotic disease. Arterioscler Thromb Vasc Biol 17:2309-2315

23. Kinsella BT 2001 Thromboxane A2 signalling in humans: a 'tail' of two receptors Biochem Soc Trans 29:641-654
24. Haworth SG, Hislop AA 1981 Adaptation of the pulmonary circulation to extrauterine life in the pig and its relevance to the human infant. Cardiovasc Res 15:108-119

25. Arrigoni FI, Hislop AA, Haworth SG, Mitchell JA 1999 Newborn intrapulmonary veins are more reactive than arteries in normal and hypertensive piglets. Am J Physiol 277:L887-L892

26. Tazzeo T, Miller J, Janssen LJ 2003 Vasoconstrictor responses, and underlying mechanisms, to isoprostanes in human and porcine bronchial arterial smooth muscle. Br J Pharmacol 140:759-763

27. González-Luis G, García-Muñoz F, Pérez-Vizcaíno F, De Mey JG, Blanco CE Villamor E 2004 Vasorelaxant actions of isoprostanes in neonatal porcine pulmonary, mesenteric, and coronary vascular smooth muscle. Pediatr Res 55:587A

28. Cogolludo A, Moreno L, Bosca L, Tamargo J, Perez-Vizcaino F 2003 Thromboxane A2-induced inhibition of voltage-gated $\mathrm{K}+$ channels and pulmonary vasoconstriction: role of protein kinase Czeta. Circ Res 93:656-663

29. Di Mari JF, Mifflin RC, Adegboyega PA, Saada JI, Powell DW 2003 IL-1alphainduced COX-2 expression in human intestinal myofibroblasts is dependent on a PKCzeta-ROS pathway. Gastroenterology 124:1855-1865

30. Bailly K, Ridley AJ, Hall SM, Haworth SG 2004 RhoA activation by hypoxia in pulmonary arterial smooth muscle cells is age and site specific. Circ Res 94:1383-1391

31. Schmalfuss CM, Chen LY, Bott JN, Staples ED, Mehta JL 1999 Superoxide anion generation, superoxide dismutase activity, and nitric oxide release in human internal mammary artery and saphenous vein segments. J Cardiovasc Pharmacol Ther 4:249-257

32. Raj JU, Hillyard R, Kaapa P, Gropper M, Anderson J 1990 Pulmonary arterial and venous constriction during hypoxia in 3- to 5-wk-old and adult ferrets. J Appl Physiol 69:2183-2189

33. Gao Y, Tolsa JF, Botello M, Raj JU 1998 Developmental change in isoproterenolmediated relaxation of pulmonary veins of fetal and newborn lambs. J Appl Physiol 84:1535-1539

34. Edelstone DI, Holzman IR 1982 Fetal intestinal oxygen consumption at various levels of oxygenation. Am J Physiol Heart Circ Physiol 242:H50-H54

35. Su BY, Reber KM, Nankervis CA, Nowicki PT 2003 Development of the myogenic response in postnatal intestine: role of PKC. Am J Physiol Gastrointest Liver Physiol 284:G445-G452

36. Saugstad OD Update on oxygen radical disease in neonatology. Curr Opin Obstet Gynecol 13:147-153, 2001

37. Nozik-Grayck E, Dieterle CS, Piantadosi CA, Enghild JJ, Oury TD 2000 Secretion of extracellular superoxide dismutase in neonatal lungs. Am J Physiol Lung Cell Mol Physiol 279:L977-L984 